\title{
Análise da dinâmica da ocupação territorial em Fortaleza-CE, Brasil: o desafio do município em promover funções ambientais e econômicas
}

\section{Renata Locarno Frota ${ }^{1}, *$ Samiria Maria Oliveira da Silva ${ }^{2}$, Francisco Suetônio Bastos Mota $^{3}$ e Francisca Dalila Menezes Vasconcelos ${ }^{3}$}

\author{
${ }^{1}$ Universidade Federal do Ceará. Programa de Pós-Graduação em Recursos \\ Hídricos. Campus do Pici. Bloco 713. Fortaleza-CE, Brasil (CEP 60455-900). E-mail: \\ renata.locarno@hotmail.com. \\ ${ }^{2}$ Universidade Federal do Ceará. Departamento de Engenharia Hidráulica e \\ Ambiental. Campus do Pici. Bloco 713. Fortaleza-CE, Brasil (CEP 60455-900). \\ ${ }^{3}$ Universidade Federal do Ceará. Programa de Pós-Graduação em Engenharia Civil. \\ Campus do Pici. Bloco 713. Fortaleza-CE, Brasil (CEP 60455-900).
}

Resumo. As relações existentes entre sociedade e natureza ao longo dos anos tem refletido em ações de gestão ambiental e em diferentes leis para a proteção dos recursos ambientais. Nos níveis federal e municipal foram criados mecanismos de preservação, como a Área de Preservação Permanente (APP) e a Zona de Proteção Ambiental (ZPA-1). Portanto, este estudo visa a analisar a dinâmica da ocupação territorial do município de Fortaleza e verificar se a Lei Complementar no 250/2018 cumpre suas funções econômicas e ambientais. Para isso, foi aplicado técnicas de geoprocessamento e avaliado se a APP possui dimensões apropriadas em relação a ZPA-1, identificado as áreas de intensa especulação imobiliária e apresentado uma evolução das áreas de interesse econômico. Verificou-se que a ZPA-1 possui uma área maior que a APP, porém, ao longo dos anos, as leis municipais e estaduais não consideram trechos suprimidos e transformados, isto é, aqueles que perderam sua função ambiental. Vale ressaltar que algumas áreas da ZPA-1 possuem largura inferior ao mínimo de $30 \mathrm{~m}$ exigido pela lei federal, portanto, a legislação municipal nem sempre obedece à lei federal. Dessa forma, o estudo aponta a necessidade de implementação de ferramentas legais e administrativas integradas e alinhadas nos níveis municipal, estadual e federal para aplicação de uma gestão adequada.

Palavras-chave: Especulação imobiliária; Expansão urbana; Plano diretor.

Abstract. Analysis of the dynamics of territorial occupation in Fortaleza-CE, Brazil: The city's challenge in promoting environmental and economic functions. Over the years, the
Recebido

$16 / 08 / 2020$

Aceito

$10 / 06 / 2021$

Disponível on line

$27 / 06 / 2021$

Publicado

$31 / 08 / 2021$

Acesso aberto

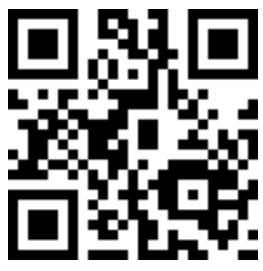

ORCID

D) $0000-0003-1381-1702$ Renata Locarno Frota

D 0000-0002-8976-7229

Samiria Maria Oliveira da Silva

ISSN 2359-1412/RBGAS-2020-0126/2021/8/19/7/759

Rev. Bras. Gest. Amb. Sustent.

http://revista.ecogestaobrasil.net 
relationships between society and nature have been reflected in environmental management actions and in different laws for the protection of environmental resources. At the federal and municipal levels, preservation mechanisms were created, such as the permanent preservation area (PPA) and the environmental protection zone (EPZ-1). Therefore, this study aims to analyze the dynamics of territorial occupation in Municipality of Fortaleza and to verify whether the Complementary Law No. 250/2018 fulfills its economic and environmental functions. For that, geoprocessing techniques were applied and evaluated if the PPA has appropriate dimensions concerning the EPZ-1, identified the areas of intense real estate speculation, and presented an evolution of economic interest. It was found that the EPZ-1 has a larger area than the PPA, however, over the years, municipal and state laws have not considered sections suppressed and transformed, that is, those that have lost their environmental function. Besides, municipal legislation does not always comply with federal law. It is worth mentioning that some areas of EPZ-1 have a width less than the minimum of 30 meters required by federal law. Therefore, municipal legislation does not always comply with federal law. Thus, the study points out the need to implement integrated and aligned legal and administrative tools at the municipal, state, and federal levels to apply adequate management.

Keywords: Master Plan; Real Estate Speculation; Urban Expansion.

\section{Introdução}

Água, sistemas econômicos, atividades humanas e valoração do solo estão profundamente conectados causando efeitos diretos e feedbacks indiretos nas escalas urbana e regional e requerendo um gerenciamento eficaz e integrado das áreas ambientais (Pan et al., 2018).

A intensificação das atividades humanas resultou em alterações ambientais significativas, incluindo transformações nos recursos hídricos, tanto em qualidade quanto em quantidade gerando soluções desafiadoras para o controle desses ecossistemas (Wang et al., 2019). Segundo McGrane (2016), a expansão mundial das áreas urbanas causou mudanças marcantes nos processos naturais, na qualidade ambiental e no consumo de recursos naturais. 0 ciclo hidrológico nestas áreas é afetado pelas modificações nos componentes de infiltração, escoamento e evaporação. Portanto, devido à urbanização, ele foi desestabilizado (Sharma, 2017).

À medida que as populações humanas se tornam cada vez mais urbanas, os tomadores de decisão em todos os níveis enfrentam novos desafios relacionados à escala da prestação de serviços e à crescente complexidade das cidades e das redes que os conectam. Esses desafios podem assumir aspectos únicos em cidades com diferentes culturas, estruturas políticas e institucionais e em diferentes níveis de desenvolvimento, mas frequentemente têm em comum a interação de sistemas humanos e ambientais e as relações de feedback que governam sua evolução dinâmica. 0 gerenciamento dos recursos hídricos nas e para as cidades é uma área em que essas abordagens são promissoras (Rietveld, 2016; Skrydstrup et al., 2020). 
Segundo Kumar et al. (2016), a gestão é vista como um conjunto de instalações, regras operacionais e incentivos (economia, regulamentação, judicial e pressão social) aplicados aos recursos hídricos e relacionados ao solo em seu estado natural, por meio de um arranjo institucional envolvendo um meio de entidades relacionadas ou não à água, públicas e privadas, e suas regras e regulamentos.

O design, o desenvolvimento e a operação da infraestrutura hídrica urbana atual e futura em muitas partes do mundo dependem cada vez mais dos princípios do desenvolvimento sustentável e aplicação destes. 0 objetivo é tentar gerenciar os recursos hídricos urbanos como um "ciclo total da água" para refletir as complexidades e interconexões entre os diferentes setores e aspectos do gerenciamento urbano da água (Jalilov et al., 2018).

A história aponta que a maioria das cidades brasileiras cresceu e se desenvolveu de forma aleatória, sem seguir um plano pré-estabelecido para expansão. Atualmente, leis apropriadas devem ser a base desse crescimento, que favoreça a proteção do meio ambiente e o bem-estar dos cidadãos, sem prejuízo no desenvolvimento de atividades econômicas com benefícios sociais, educacionais e culturais (Vasconcelos e Coriolano, 2008; Silva et al., 2019).

Nesse país, vários estados como o Ceará apresentam uma inconsistência nas responsabilidades do Município e do Estado. 0 primeiro gerencia o uso do solo para promover um ordenamento adequado para a ocupação do solo urbano, já o Estado tem a responsabilidade de proteção do meio ambiente. Como exemplo, no Estado de São Paulo tem-se a Lei no 9.866/1997 (São Paulo, 1997), que estabelece que nas Áreas de Proteção e Recuperação dos Mananciais as diretrizes e normas ambientais e urbanísticas de interesse regional serão criadas através de lei estadual. Um dos problemas dessa responsabilidade é que os limites das bacias hidrográficas não coincidem com os limites dos estados; portanto, a compartimentação geográfica e político-administrativa não são as mesmas, criando impasses e dificultando ações regulatórias e de fiscalização (Ancona, 2007).

Segundo Vasconcelos e Coriolano (2008), a velocidade das ações públicas tem sido menor que a velocidade do crescimento urbano. Além disso, não há inspeção ou controle legal efetivo que impeça ações prejudiciais ao meio ambiente existindo um abismo entre o que é planejado e o que é executado.

Além disso, o planejamento urbano é limitado pelos interesses do mercado, inclusive priorizando a infraestrutura em espaços mais ricos e valorizados. Para Friedmann (1987) e Frota (2018), é observado a mercantilização do solo urbano, onde são priorizados os interesses de grupos específicos, e há substituição de espaços públicos abertos por áreas construídas.

Dois instrumentos colaboram para a gestão ambiental urbana, o Estatuto da Cidade e o Plano Diretor. Segundo Fernandes et al. (2014), o Estatuto da Cidade, Lei no 10.257/2001 (Brasil, 2001), que visa a democratizar a gestão das cidades brasileiras por meio de instrumentos de gestão, estabelece que cada município deve elaborar seu Plano Diretor como um dos instrumentos de política urbana e planejamento do uso do solo. Assim, a cidade de Fortaleza, localizada no Ceará, é responsável pela elaboração do seu Plano Diretor.

O Plano Diretor de Fortaleza, instituído pela Lei Complementar no 62/2009, pretende cumprir seus princípios de Política Urbana. Entre eles, encontramos a verificação das funções sociais e ambientais da cidade, que inclui a preservação e conservação do meio ambiente, garantindo a proteção dos ecossistemas e recursos ambientais existentes e garantindo a todos os habitantes um ambiente ecologicamente equilibrado.

Ele objetiva, principalmente, considerar, no processo de planejamento e execução das políticas públicas, a integração social, econômica, ambiental e territorial; construir um sistema democrático e participativo de planejamento e gestão da cidade; regular o uso, ocupação e parcelamento do solo urbano; combater a especulação imobiliária; preservar o 
patrimônio cultural do interesse artístico, estético, histórico, turístico e paisagístico; ampliar a oferta de áreas de produção habitacional de interesse social com qualidade, voltadas aos segmentos de baixa renda (Fortaleza, 2009).

O Plano Diretor de Fortaleza delimita a macrozona de proteção ambiental em I Zona de Proteção Ambiental (ZPA); II - Zona de Recuperação Ambiental (ZRA); e III - Zona de Interesse Ambiental (ZIA). A ZPA tem como objetivo preservar ecossistemas e recursos naturais e é dividida em I - ZPA 1 - Faixa de Preservação Permanente dos Recursos Hídricos; II - ZPA 2 - Faixa de Praia; III - ZPA 3 - Parque Natural Municipal das Dunas de Sabiaguaba (Fortaleza, 2009).

Segundo o art. 64, da Lei Complementar no 62/2009, os objetivos da ZPA envolvem a preservação de sistemas naturais, permitindo apenas o uso indireto dos recursos naturais; promover a realização de estudos e pesquisas científicas; desenvolvimento de atividades de educação e interpretação ambiental; turismo ecológico; preservar sítios naturais, singulares ou de grande beleza cênica; proteger ambientes naturais nos quais sejam garantidas condições para a existência ou reprodução de espécies ou comunidades da flora local e fauna residente ou migratória; e garantir o uso público das praias (Fortaleza, 2009).

A principal distinção entre a área de preservação permanente e a zona de proteção ambiental é que uma é uma área delimitada pelo Código Florestal, ou seja, uma lei federal, enquanto a outra é uma lei municipal, o Plano Diretor. Assim, a lei federal está acima da lei municipal. No entanto, esses dois instrumentos têm a mesma função ambiental para proteger os recursos hídricos.

Vinculada ao Plano Diretor de Fortaleza, existe a Lei Complementar no 250/2018 (Fortaleza, 2018) que delimita novas zonas de proteção ambiental, redefinindo algumas áreas. Essa lei transforma os limites de algumas áreas como a Zona de Requalificação Urbana 2 (ZRU 2), a Zona de Interesse Ambiental do Cocó (ZIA 3) e as Zonas de Proteção Ambiental.

A delimitação dessas áreas não deve considerá-las como ambientes isolados, mas associados a outros componentes do meio pois, uma alteração em um dos meios pode causar modificações quantitativas e qualitativas no todo (Mota, 2019).

A zona ribeirinha, por exemplo, fornece uma variedade de recursos para os organismos, incluindo a disponibilidade de água e subsídios. No entanto, ecossistemas aquáticos e zonas ribeirinhas são propensas a distúrbios antropogênicos, que alteram a disponibilidade de água e afetam a dinâmica de fluxo dos subsídios entre sistemas (Xiang, 2016). A qualidade das zonas ribeirinhas está inversamente relacionada ao grau de urbanização das áreas adjacentes. Além disso, os usos do solo que fornecem cobertura florestal garantem uma condição menos degradada e uma maior diversidade de espécies (Diaz-Pascacio et al., 2018).

Segundo Wang (2018), a capitalização da terra que resultou de uma rápida urbanização aliada aos efeitos de políticas regionais de uso do solo causou danos nos ecossistemas. Assim, faz-se necessário analisar a dinâmica de uso do solo num contexto geral, ou seja, em conjunto com a dinâmica social, ambiental e econômica.

Huang et al. (2019) e Wang et al. (2018, 2020) aplicaram técnicas de sensoriamento remoto para analisar o desempenho do uso do solo considerando os fatores ambientais, sociais, políticos e econômicos. Assim como Pan et al. (2018) aplicaram um modelo de sistemas acoplados de uso regional da terra, economia e interações do sistema de água em dois casos urbanos (Chicago e Estocolmo) para criar cenários futuros desses impactos.

Diferentes relações entre sociedade e natureza em cada país refletem em ações de gestão ambiental e em diferentes leis para a proteção dos recursos hídricos (Vasconcelos e Mota, 2020). Na França, as intervenções humanas nos leitos dos rios ocorreram há muito tempo para o desenvolvimento das cidades sem atentar-se à questão ambiental. 
Entretanto, em 2010, uma lei determinou a proteção da vegetação herbácea ou florestal, pelo menos cinco metros por proprietários rurais (Gass et al., 2016). Nos Estados Unidos, por outro lado, cada Estado é responsável por delimitar e proteger suas áreas de proteção ambiental (APPs) caracterizando o gerenciamento descentralizado (Pedroso Júnior et al., 2015). Essa gestão é semelhante à administração praticada no Brasil.

O objetivo deste estudo é analisar a dinâmica da ocupação territorial do município de Fortaleza e verificar se a Lei Complementar no 250/2018 (Fortaleza, 2018) cumpre suas funções econômicas e ambientais possibilitando o desenvolvimento da cidade e a manutenção das áreas de preservação.

O estudo utilizou variáveis ambientais (APP - área de preservação permanente e ZPA - zona de proteção ambiental) e econômicas (valor do solo, alvarás de construção) e por meio de técnicas de avaliou comparou as áreas de APP com ZPA, identificado as áreas de intensa especulação imobiliária e apresentado uma evolução das zonas de interesse econômico. A base de dados e o método utilizado possibilitam que o estudo possa ser replicado para outras cidades brasileiras.

\section{Área de preservação permanente no Brasil}

Segundo Milaré (2015), nos séculos XVI e XVII, quando o Brasil era uma colônia portuguesa havia evidências das primeiras normas de proteção dos recursos naturais, que proibiam a caça de certos animais e o corte de árvores frutíferas.

O primeiro Código Florestal Brasileiro foi editado em 1934 (Brasil, 1934) e essas áreas eram chamadas apenas de florestas protetoras (Lopes et al., 2017). Esse código passou por algumas mudanças ao longo dos anos. A Figura 1 apresenta uma linha do tempo com os principais acontecimentos.

Assim, a regulamentação de 1934 tinha um caráter técnico voltado para conservação de funções básicas do ecossistema. Durante o período que se sucedeu os sistemas da cafeicultura e da criação extensiva de gado dizimaram as florestas e vegetações nativas.

Contudo, a visão de acesso aos recursos para as gerações atuais e futuras foi questionada apenas em 1950 (Lopes e Alencastro, 2008). Assim o Código Florestal sofreu mudanças e em 1965 surgiu o "Novo" Código Florestal, onde se apresentou o conceito de Área de Preservação Permanente e a Amazônia Legal. 0 novo Código Florestal apresentou-se de forma sintética em relação ao primeiro Código Florestal, pois um possuía 50 artigos enquanto o outro 101. Entretanto, o novo Código Florestal mostrou-se com aprimoramentos e adequações. Observa-se que entre seus objetivos principais tem-se a preocupação de proteção dos recursos hídricos, encostas muito declivosas, áreas topograficamente diferenciadas, ambientes costeiros, dentre outros.

O Novo Código Florestal passou por mais uma modificação, com a Lei no 12.651/2012 (Brasil, 2012). Ele encontra-se em vigor atualmente e é palco de controvérsias, pois promoveu a proteção de forma menos restritiva se comparada ao Código de 1965 (Carvalho, 2014). Uma das modificações preconizadas no Código Florestal esteve relacionada aos limites das APPs. Foi realizada a exclusão das chamadas nascentes intermitentes, mantendo a necessidade de um raio mínimo de $50 \mathrm{~m}$ ao redor das nascentes e olhos d'água perenes. Além disso, o conceito de área rural consolidada também foi instituído para a liberação da recomposição das APPs indevidamente ocupadas antes de 22 de julho de 2008 (Leite et al., 2020). Outra modificação foi a alteração do parâmetro para mensurar APPs, que antes era feito a partir do seu nível mais alto e passou a ser da borda da calha do leito regular do curso de água. Isso reduziu substancialmente essas áreas protegidas acarretando a possibilidade de ocupação do leito maior de cursos de água. Além disso, dispensou-se a necessidade de reservar uma faixa de proteção no entorno das acumulações naturais ou artificiais de água com superfície inferior a um hectare (Lopes et al., 2017). 


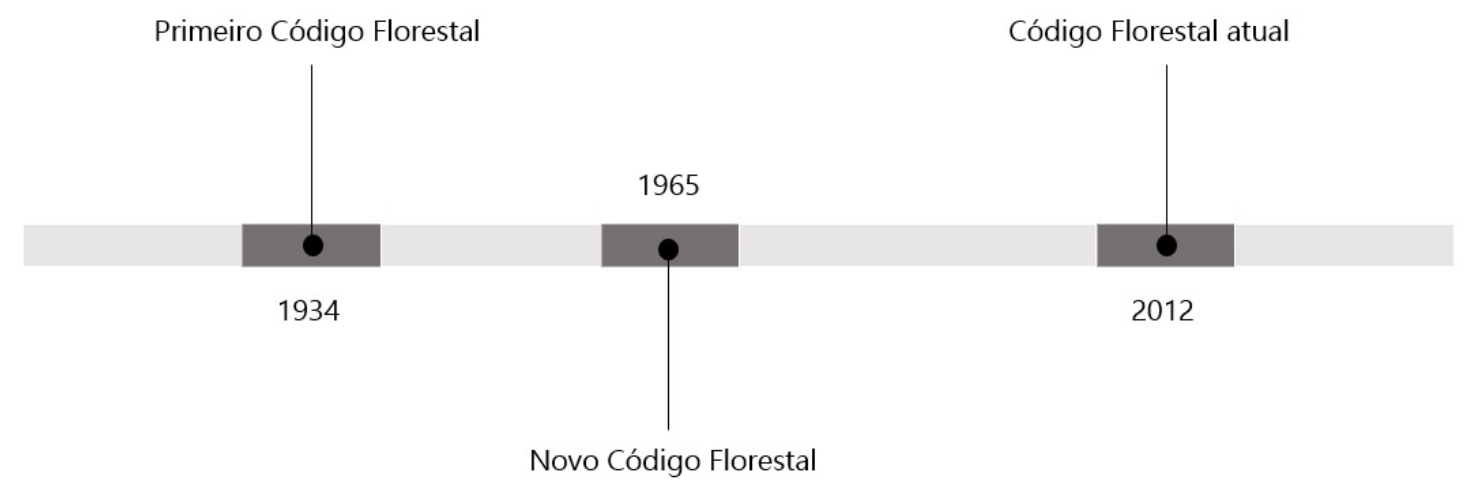

Figura 1. Linha do tempo do Código Florestal.

As funções ambientais das APPs encontram-se previstas no art. 3ㅜㅡ, inciso II, do Código Florestal vigente, que é o de preservar os recursos hídricos, a paisagem, a estabilidade geológica e a biodiversidade, facilitar o fluxo gênico da fauna e da flora, proteger o solo e assegurar o bem-estar das populações humanas (Brasil, 2012).

Além da proteção dos recursos hídricos, as APPs foram criadas para a preservação das matas ciliares, ou seja, vegetação às margens de rios e córregos, exercendo função de instrumento redutor do assoreamento, da degradação do meio ambiente e de cheias (Castro, 2013).

\section{Materiais e métodos}

Como objeto de estudo foi escolhida a Município de Fortaleza, capital do Ceará, que está localizada no Nordeste do Brasil. Ela possui uma área de $312.407 \mathrm{~km}^{2}$ e uma população estimada de 2.669.342 (IBGE, 2019).

A urbanização de Fortaleza iniciou-se de forma mais acelerada nas décadas de 1950 e 1960, onde os bairros mais distantes do centro começaram a ser massivamente ocupados, dando lugar ao Meireles e Aldeota, que abrigam as elites. Neste período também, deu-se início ao desenvolvimento das favelas e a falta de estrutura pública para a população de baixa renda. Em 1963, teve-se a construção Avenida Beira Mar, o que fortaleceu a exploração turística da cidade (Bruno e Farias, 2012).

Para analisar os impactos ambientais e econômicos em Fortaleza foram utilizados os seguintes dados:

I. Informações sobre as lagoas e rios de Fortaleza em formato shapefile, obtidos do site do Instituto de Planejamento de Fortaleza (IPLANFOR), atualizados em 20/11/2018.

II. Os valores de referência do solo para o Imposto sobre Terrenos e Imóveis Urbanos (IPTU) no formato shapefile, obtidos do site da Instituto de Planejamento de Fortaleza (IPLANFOR), atualizado em 20/11/2018.

III. Informações sobre as limitações da ZPA-1 no formato shapefile, obtidos do site da Secretaria Municipal de Urbanismo e Meio ambiente (SEUMA), atualizado em 07/12/2018. 
IV. Os alvarás de construção em formato KML, obtidos do site da da Secretaria Municipal de Urbanismo e Meio ambiente (SEUMA), atualizados em 2020.

As etapas metodológicas podem ser visualizadas na Figura 2.

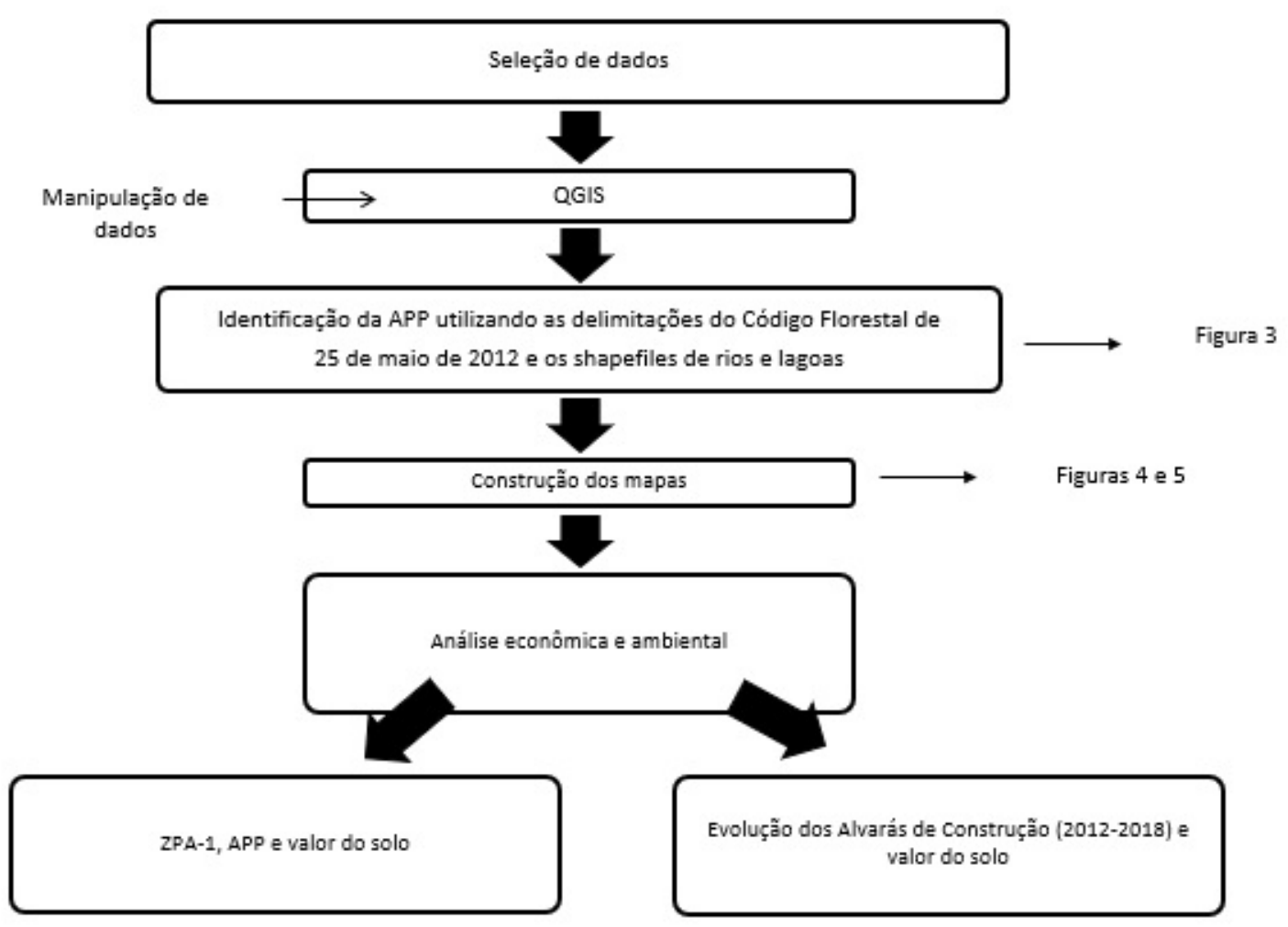

Figura 2. Etapas metodológicas.

Primeiro, a seleção de dados: shapefiles de rios e lagoas, alvarás de construção de 2012 a 2018 em KML. Em seguida, foi realizada a manipulação de dados no software QGIS. 0 terceiro passo foi a identificação da APP conforme a delimitação prescrita no art. $4^{\circ}$, da Lei no 12.651/2012 (Brasil, 2012). 0 quarto passo foi a construção dos mapas de APP, ZPA e alvarás de construção. $O$ último passo foi a análise ambiental e econômica observando os aspectos quantitativos de preservação de ambos os instrumentos e a organização espacial da cidade onde verificou-se a evolução dos empreendimentos construídos.

Aplicou-se o software livre QGIS para manipulação de dados. Este software é uma ferramenta para apresentar e processar dados de informações espaciais. É um sistema capaz de capturar, armazenar e analisar informações geograficamente referenciadas. A combinação de dados espaciais com várias informações estatísticas disponíveis no GIS fornece suporte aos tomadores de decisão para um melhor planejamento do crescimento da comunidade.

É necessário enunciar que os shapefiles usam dados geoespaciais, portanto, é possível observar apenas os rios que são visíveis nas imagens de satélite, sendo aqueles extremamente pequenos ou canalizados não mostrados nos shapefiles. Além disso, para 
fins comparativos, na ZPA-1, apenas a proteção de rios e lagoas foi considerada, desconsiderando-se as áreas de dunas e manguezais.

Em seguida, foram adotadas as delimitações consideradas no Código Florestal de 25 de maio de 2012, que é a lei atual, para identificar as áreas de APP. Utilizando o software QGSIS e suas ferramentas, mediu-se o comprimento dos rios e lagoas e calculou-se suas larguras mínimas a partir da margem, de acordo com o Código Florestal.

Art. 4o Considera-se Área de Preservação Permanente, em zonas rurais ou urbanas, para os efeitos desta Lei:

I - as faixas marginais de qualquer curso d'água natural perene e intermitente, excluídos os efêmeros, desde a borda da calha do leito regular, em largura mínima de: (Incluído pela Lei no 12.727, de 2012).

a) 30 (trinta) metros, para os cursos d'água de menos de 10 (dez) metros de largura;

b) 50 (cinquenta) metros, para os cursos d'água que tenham de 10 (dez) a 50 (cinquenta) metros de largura;

c) 100 (cem) metros, para os cursos d'água que tenham de 50 (cinquenta) a 200 (duzentos) metros de largura;

d) 200 (duzentos) metros, para os cursos d'água que tenham de 200 (duzentos) a 600 (seiscentos) metros de largura;

e) 500 (quinhentos) metros, para os cursos d'água que tenham largura superior a 600 (seiscentos) metros;

II - as áreas no entorno dos lagos e lagoas naturais, em faixa com largura mínima de:

a) 100 (cem) metros, em zonas rurais, exceto para o corpo d'água com até 20 (vinte) hectares de superfície, cuja faixa marginal será de 50 (cinquenta) metros;

b) 30 (trinta) metros, em zonas urbanas;

Para as análises ambientais, mapas de APP e ZPA-1 foram feitos para comparar essas zonas, a fim de verificar qualitativamente suas áreas e outros instrumentos de preservação presentes.

Para análise econômica elaborou-se um mapa de calor dos Alvarás de Construção para cada ano para que fosse possível observar a evolução das áreas de interesse das construtoras para construção de empreendimentos. Considerou-se o horizonte temporal de 2012 a 2018, pois o ano de 2019 estava incompleto.

\section{Resultados e discussão}

\section{Análise ambiental}

A delimitação de ZPA-1 e APP, conforme a Lei Complementar no 250/2018 (Fortaleza, 2018), está apresentada na Figura 3. Esta figura foi elaborada considerando as larguras mínimas de rios e lagoas sem remover o espelho d'água. 


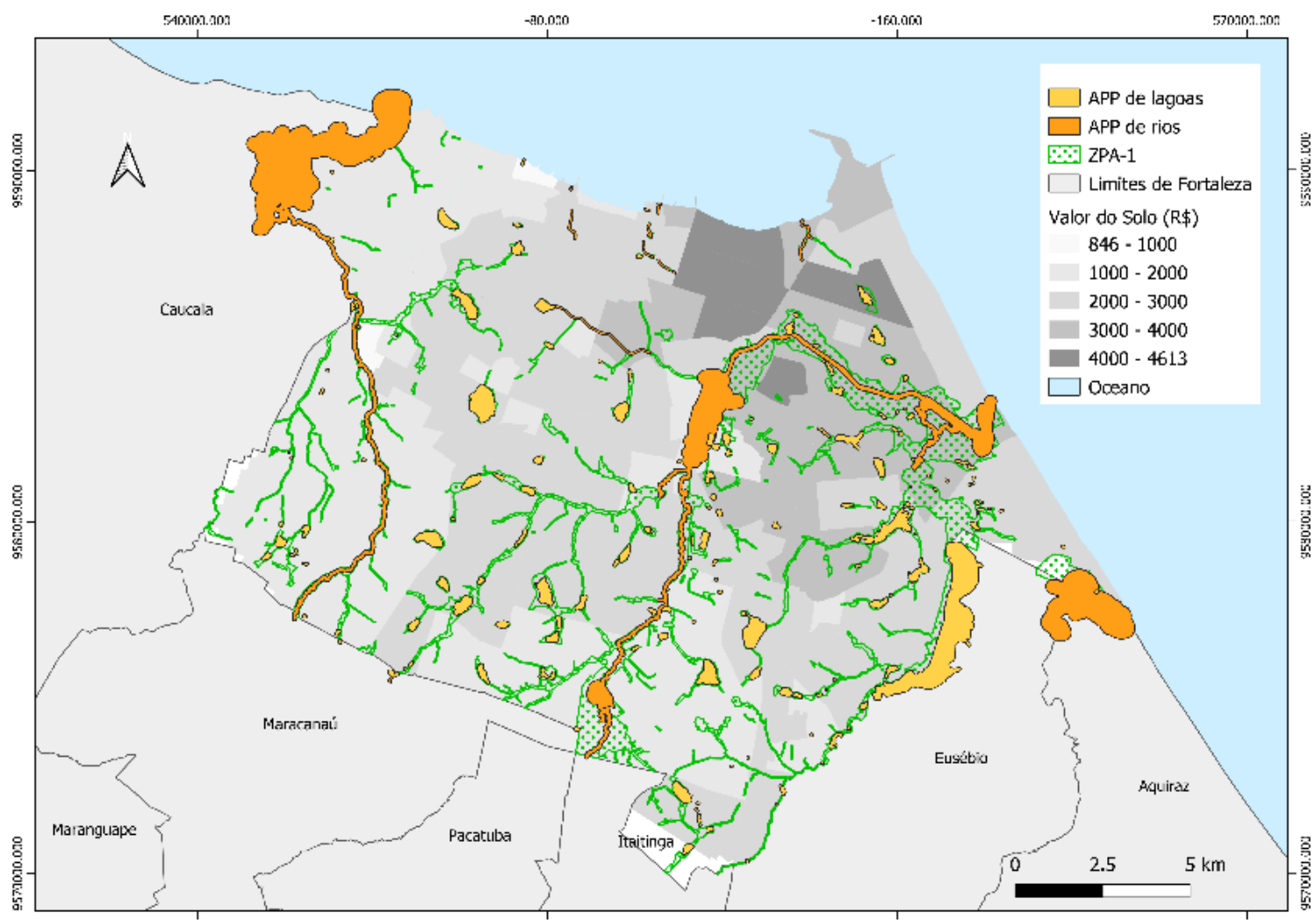

Figura 3. Representação de ZPA-1 e APP de rios e lagoas em Fortaleza (CE), Brasil, 2020.

Com base na Figura 3, a APP das lagoas ocupa uma área de $11,8 \mathrm{~km}^{2}$ e a APP dos rios, $20,2 \mathrm{~km}^{2}$, resultando em $32 \mathrm{~km}^{2}$, o que representa $10,22 \%$ do território de Fortaleza. Já a área da ZPA-1 (Lei Complementar no 250/2018) é de 40,6 km² e 12,97\% do território de Fortaleza.

Rocha (2015) realizou uma análise com a ZPA-9 e APPs em Natal, localizado no estado do Rio Grande do Norte, Brasil, utilizando GPS e imagens de satélite. A ZPA-9 é caracterizada por seu ecossistema de lagoas e dunas ao longo do rio Doce, ou seja, é uma zona de proteção dos recursos hídricos.

O leito regular do Rio Doce dentro dos limites da ZPA-9 tem uma área total de $0,36 \mathrm{~km}^{2}$. Além disso, a APP total para o Rio Doce encontrada no Código Florestal de 2012 foi de $3,3 \mathrm{~km}^{2}$ (Rocha, 2015). Nesse caso, observou-se que a área da ZPA era inferior à área de APP, mas vale ressaltar que, como no Ceará, no Rio Grande do Norte há incompatibilidade de leis, que acabam reduzindo a área real de preservação ambiental.

Em Fortaleza, a ZPA-1 possui uma área $21,15 \%$ maior que a da APP. Porém, é necessário ressaltar que a APP desconsidera trechos canalizados, efêmeros, e aqueles transformados pela urbanização. Ao longo dos anos, esses trechos têm sido considerados como tendo sua função ambiental perdida. Apesar disso, é essencial questionar o que é perder a função ambiental, pois esses rios fazem parte do sistema de drenagem urbana e, diante das chuvas, o encanamento não os suporta, causando inundações.

Além das inundações, a paisagem em potencial, o controle de erosão e assoreamento, e o filtro de nutrientes fazem parte da função ambiental.

O conflito de supressão de APPs devido aos trechos canalizados/transformados resultou na redução de $961.185,34 \mathrm{~m}^{2}$ de APPs nas margens dos recursos hídricos em 
Fortaleza comparando os requisitos da Lei Complementar no 250/2018 com os da legislação brasileira, Código Florestal (Vasconcelos e Mota, 2020).

Portanto, se forem considerados todos os trechos de rios canalizados para o cálculo então a área de APP se torna mais significativa que a de ZPA-1. Vale ressaltar que algumas áreas da ZPA-1 possuem largura inferior ao mínimo de 30 metros exigido pela lei federal, portanto, a legislação municipal nem sempre obedece à lei federal.

Além disso, em vários casos, a ZPA-1 deve proteger mais de 30 m nas margens dos recursos hídricos, pois essa medida depende da largura das calhas do leito regular dos cursos de água (Vasconcelos e Mota, 2020).

Lopes et al. (2017) justifica que existe uma proteção deficiente para a proteção de APPs, que atinge o núcleo essencial do direito fundamental ao ambiente ecologicamente equilibrado, sendo insuficiente para resguardar áreas de manutenção da biodiversidade a longo prazo. Posteriormente, reflete-se que o Plano Diretor e as ZPA cumprem suas funções de proteção dos recursos ambientais previstos em lei, entretanto, a lei se mostra insuficiente para uma verdadeira proteção dos ecossistemas e recursos ambientais existentes.

\section{Análise econômica}

Verificou-se que em áreas com maior valor de solo, como Cocó, Guararapes e Edson Queiroz, foi observada maior área de ZPA-1, pois, devido ao mercado imobiliário, se torna atraente construir perto de regiões arborizadas, o que aumenta a especulação imobiliária. A Figura 4 apresenta essas áreas em cor mais escura.

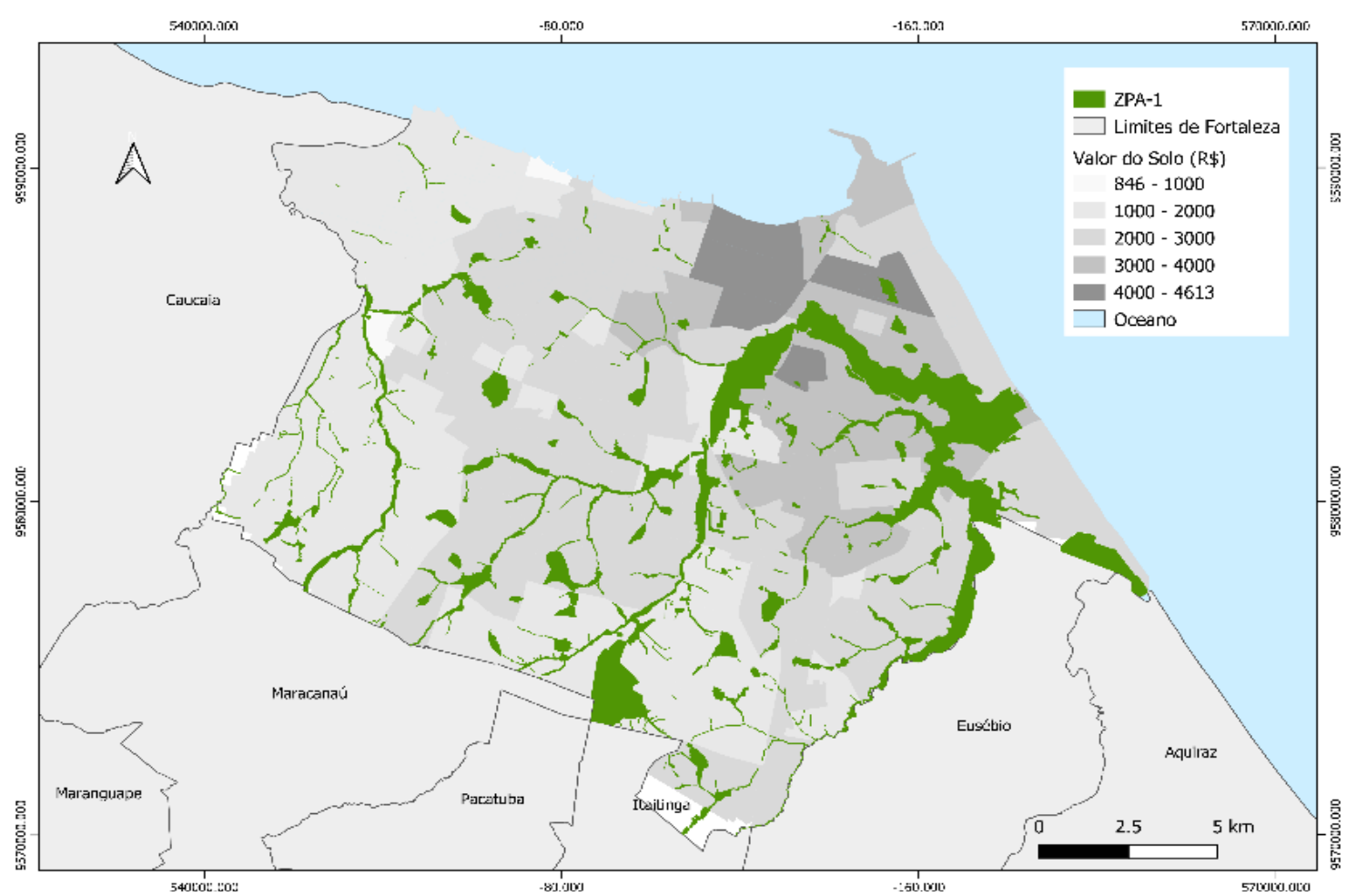

Figura 4. Área de Preservação Ambiental e Valor do Solo em Fortaleza, Ceará, Brasil, 2020.

Além disso, em 2017, o estado incorporou a Unidade de Conservação de Uso Sustentável do Rio Cocó no macrozoneamento de Fortaleza. Unidades de conservação são áreas ambientalmente relevantes do Sistema Nacional de Unidades de Conservação 
(SNUC), instituído pela Lei no 9.985/2000 (Brasil, 2000). As unidades de conservação são semelhantes às APPs, pois estão próximas aos recursos hídricos (Vasconcelos et al., 2019).

Verificou-se que em locais com valores mais baixos do solo existem mais rios canalizados ou lagoas subterrâneas; assim, esses trechos tiveram seu ZPA-1 reduzido em tamanho. Além disso, existe uma falta de infraestrutura urbana e saneamento, e uma incidência de assentamentos precários, o que torna essas regiões não economicamente atraentes.

Entretanto, percebe-se uma preocupação do estado com a conservação da área próxima ao Rio Maranguapinho, que recentemente se tornou uma unidade de conservação e sua APP está sendo recuperada.

A lei é mais flexível em áreas menos favorecidas, que intensificam a ocupação irregular e outros fatores prejudiciais. Isso resulta em menor valor do solo.

Frota (2018) relata a luta pela preservação de áreas verdes nas regiões do Parque do Cocó e Lagoa da Viúva, em Fortaleza, CE, Brasil. Ambos estão localizados em diferentes setores da cidade; o primeiro está localizado em uma região valorizada e o segundo em uma região com menor especulação imobiliária e com muitos assentamentos irregulares.

Nota-se que a Lagoa da Viúva está localizada em uma Zona Especial Ambiental (ZEA), que é menos protegida do que as ZPA, sendo mais sensíveis à ocupação, principalmente irregular. Assim, esses fatores reduzem o valor do solo.

Além disso, a Lagoa da Viúva não recebe proteção sob a lei de Unidades de Conservação, portanto, não pode receber recursos para a recuperação de APPs, como ocorreu no Rio Maranguapinho.

$\mathrm{Na}$ área do Rio Cocó, a estreita relação entre o Estado e o mercado imobiliário permite um maior número de áreas verdes preservadas, o que valoriza empreendimentos futuros, pois morar perto de uma área verde dentro da cidade representa uma vantagem e, portanto, um aumento no valor do uso do solo. Além disso, nessa área tem-se investimento em infraestrutura pública. Enquanto espaços livres localizados em áreas com menor valor imobiliário não recebem a devida atenção do governo e se tornam lugares vazios que sofrem intensa ocupação por parte da população de baixa renda que não possui alternativas de moradia.

Freitas (2017) utilizou a APA do Rio São Bartolomeu (Área de Proteção Ambiental) como um estudo de caso, onde explicou o padrão de segregação socioespacial da população que se utiliza da proteção ambiental para favorecer a reserva de terras para o mercado imobiliário de alta renda, deixando a população baixa renda em ocupações informais em espaços ambientalmente sensíveis.

O Município de Fortaleza possui $44 \%$ da população vivendo em assentamentos precários, ou seja, mais de 1 milhão de pessoas vivem em condições vulneráveis de habitação (Câmara Municipal de Fortaleza, 2019). Além disso, há uma desigualdade econômica significativa e uma intensa concentração de renda em uma pequena área. Dados do Instituto de Pesquisa e Estratégia Econômica do Ceará (IPECE, 2012) revelam que quarenta e quatro bairros de baixa renda respondem por $49 \%$ da população total de Fortaleza, mas possuem $26 \%$ do total da renda.

É possível verificar que o sistema capitalista seleciona ecossistemas específicos que deseja valorizar, considerando sua localização mais que seu valor ecológico. Assim, atraindo um consumidor de alta renda disposto a pagar para viver mais próximo da natureza (Freitas, 2014). Segundo Freitas (2017), o mercado imobiliário, a ordem urbanística vigente e a degradação ambiental possuem uma relação direta.

Analisando os alvarás de construção emitidos entre 2012-2018 (Figura 5) é possível observar que em 2012 os empreendimentos se concentraram na região nobre de Fortaleza, ou seja, aquela com alto valor de solo. Ao longo dos anos, observamos uma expansão para áreas mais distantes e com menor valor do solo. 
Porém, áreas com menor valor do solo, ou seja, abaixo de $\mathrm{R} \$ 2.000,00 / \mathrm{m}^{2}$, não são o foco dos projetos de construtoras para novos empreendimentos. Um dos fatores que contribuem para isso é a falta de infraestrutura nessas áreas, como transporte público e rede de esgotamento sanitário.

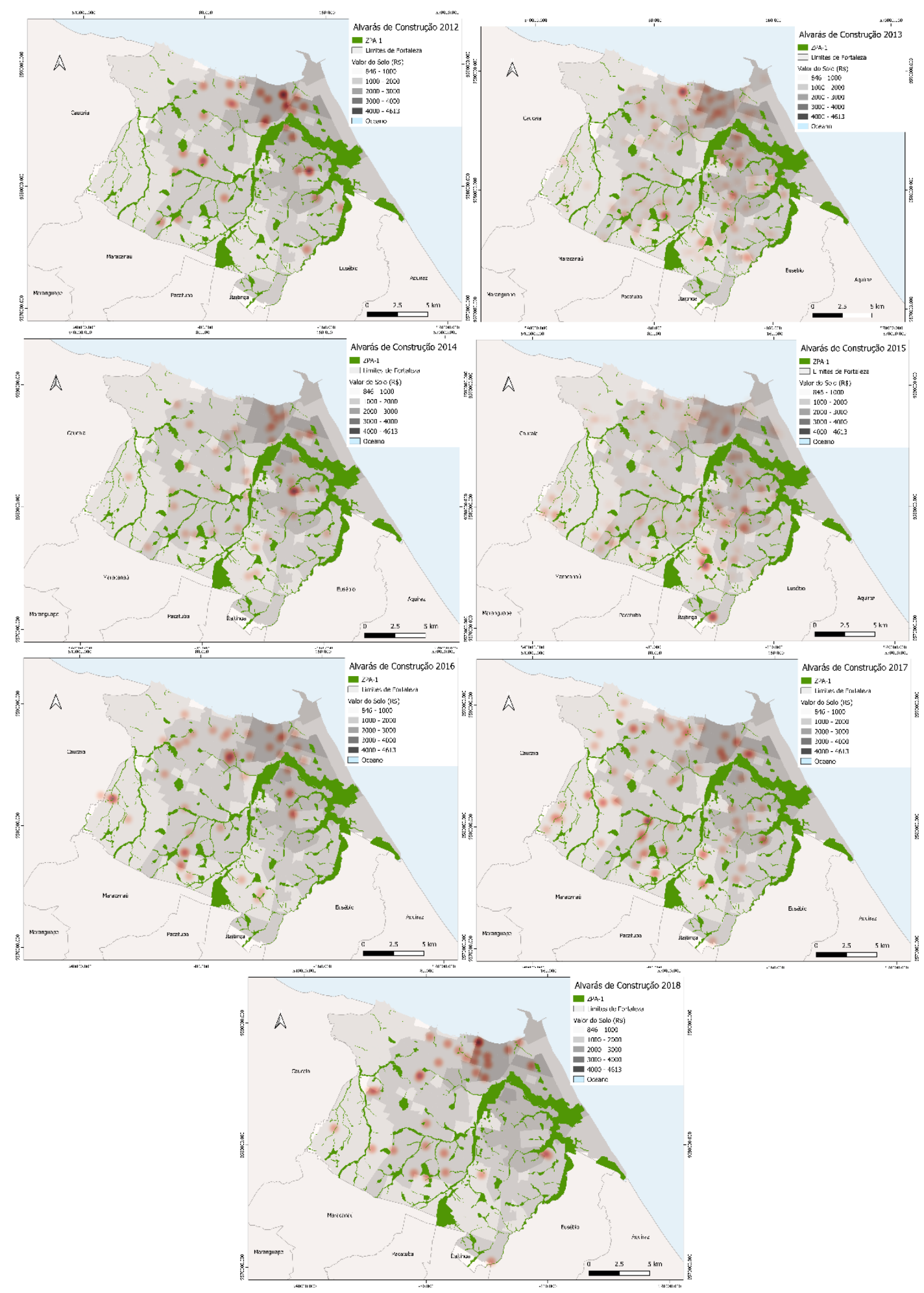

Figura 5. Mapas dos alvarás de construção emitidos entre 2012-2018 em Fortaleza, Ceará, Brasil. 
Observando a Figura 6, verifica-se que há uma redução na emissão de alvarás após 2015. Conforme Campos (2019), esta redução está relacionada com a crise econômica vivenciada pelo setor de construção civil do Brasil desde 2015. Esta crise iniciou-se com a Operação "Lava Jato" onde algumas das empresas mais influentes do país estavam supostamente envolvidas em escândalos e fraudes, causando deterioração e perturbação da economia. 0 impacto foi experimentado não apenas pelas grandes empresas, mas também pelas empresas de engenharia, gerando alto desemprego com as demissões realizadas. Assim, gerando uma reação em cadeia que afeta todos os setores.

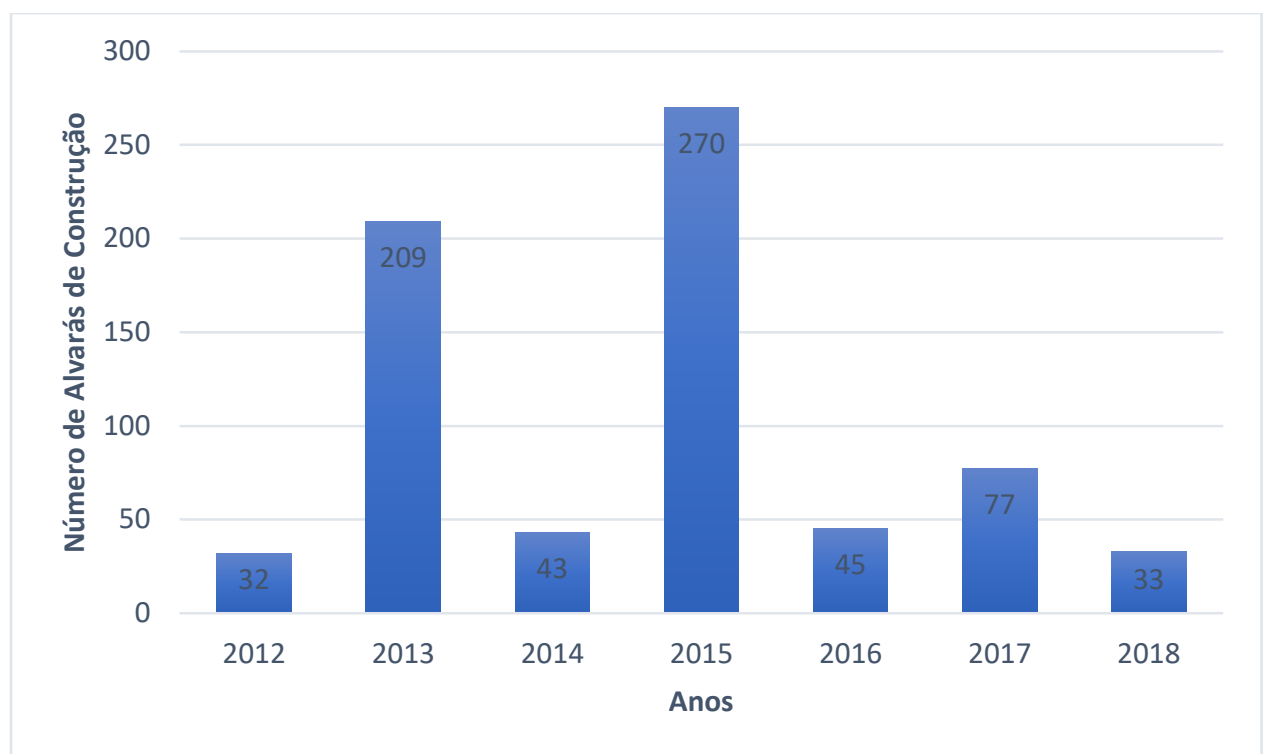

Figura 6. Número de alvarás de construção emitidos entre 2012-2018 em Fortaleza, Ceará, Brasil.

Vale ressaltar que a emissão de um alvará era realizada por meio físico e a partir de 2018, o processo tornou-se online.

Após as análises, entende-se que há uma desarticulação entre os instrumentos de gestão de recursos ambientais e os de planejamento do uso do solo refletindo a falta de legitimidade do planejamento e da legislação urbana nas cidades brasileiras (Carneiro e Miguez, 2012). Isso é causado pela ausência de legislação única que reconheça todos os níveis (municipal, estadual e federal) para que uma lei não se sobreponha a outra, evitando assim um alto grau de informalidade e não conformidade com as leis.

Além disso, o Brasil é um país vasto e ecologicamente diversificado, tornando a aplicação de uma mesma legislação um desafio para todo o território.

\section{Conclusão}

Instrumentos de gestão ambiental, como a Área de Preservação Permanente (APP) e a Zona de Proteção Ambiental (ZPA-1), são essenciais para a preservação do meio ambiente. No entanto, foi possível observar que as leis municipais, estaduais e federais nem sempre concordam na mesma área.

Verificou-se que, em Fortaleza, a ZPA-1 possui uma área maior que a APP, porém, ao longo dos anos, as leis municipais e estaduais não consideram trechos suprimidos e 
transformados, isto é, aqueles que perderam sua função ambiental. Portanto, há uma falsa impressão de que a ZPA-1 é suficiente para fornecer proteção ambiental.

0 Estado criou unidades de conservação como o Parque do Cocó e o Maranguapinho para preservar e recuperar essas áreas. No entanto, a falta de infraestrutura em áreas menos favorecidas, como transporte, segurança e saneamento básico, não permite que a população utilize esse espaço para lazer. Além disso, a falta de infraestrutura influencia o valor do solo na região.

Portanto, as funções ambientais do município não são garantidas a todos, conforme previsto no Plano Diretor de Fortaleza, mas a uma pequena parcela privilegiada da população que tem acesso à infraestrutura.

O Estado do Ceará e as entidades privadas transformam o Município de Fortaleza em mercadoria, preservando áreas economicamente convenientes e concentrando investimentos públicos para aumentar o preço do território e gerar lucros, excluindo as populações mais pobres, que se instalam em áreas sem infraestrutura ou em habitações irregulares em áreas ambientalmente sensíveis. A ocupação de APPs é um problema recorrente em cidades brasileiras densamente urbanizadas.

Além disso, os alvarás de construção mostraram a concentração de investimentos nos últimos anos. Em 2012, os investimentos foram principalmente na região nobre e, em outros anos, expandiram-se para outras áreas. No entanto, há uma redução em 2016 devido à crise financeira.

Observa-se uma inconsistência legal que exige ferramentas legais e administrativas alinhadas nos níveis municipal, estadual e federal para aplicação de uma gestão adequada.

Para os estudos subsequentes, sugere-se uma análise aprofundada da função ambiental dos trechos suprimidos e transformados para impedir tal ação nas atualizações dos planos diretores e outras leis.

\section{Agradecimentos}

Os autores agradecem à Coordenação de Aperfeiçoamento de Pessoal de Nível Superior (CAPES), ao Conselho Nacional de Desenvolvimento Científico e Tecnológico (CNPq) e à Fundação Cearense de Apoio ao Desenvolvimento Científico e Tecnológico (FUNCAP) pelo apoio financeiro.

\section{Conflito de interesses}

Os autores declaram não haver conflito de interesses.

\section{Referências}

Ancona, A. L. Moradia e mananciais: tensão e diálogo na metrópole. Pós. Revista do Programa de Pós-Graduação em Arquitetura e Urbanismo da FAUUSP, n. 22, p. 208210, 2007. https://doi.org/10.11606/issn.2317-2762.v0i22p208-210

Brasil. Decreto no 23.793, de 23 de janeiro de 1934. Approva o codigo florestal que com este baixa. Disponível em: <http://www.planalto.gov.br/ccivil_03/decreto/19301949/D23793impressao.htm>. Acesso em: 19 maio 2021.

Brasil. Lei no 9.985, de 18 de julho de 2000. Regulamenta o art. 225, § 1ํㅡ, incisos I, II, III e VII da Constituição Federal, institui o Sistema Nacional de Unidades de Conservação da Natureza e dá outras providências. Disponível em: <http://www.planalto.gov.br/ ccivil_03/LEIS/L9985.htm>. Acesso em: 19 maio 2021. 
Brasil. Lei no 10.257, de 10 de julho de 2001. Regulamenta os arts. 182 e 183 da Constituição Federal, estabelece diretrizes gerais da política urbana e dá outras providências. Disponível em: <http://www.planalto.gov.br/ccivil_03/leis/leis_2001/ 110257.htm>. Acesso em: 19 maio. 2021.

Brasil. Lei no 12.651, de 25 de maio de 2012. Dispõe sobre a proteção da vegetação nativa; altera as Leis $\mathrm{n}^{\circ} \mathrm{s}$ 6.938, de 31 de agosto de 1981, 9.393, de 19 de dezembro de 1996, e 11.428, de 22 de dezembro de 2006; revoga as Leis nos 4.771, de 15 de setembro de 1965, e 7.754, de 14 de abril de 1989, e a Medida Provisória no 2.166-67, de 24 de agosto de 2001; e dá outras providências. Disponível em: <http://www.planalto.gov.br/ ccivil_03/_ato2011-2014/2012/lei/l12651.htm>. Acesso em: 29 jul. 2020.

Bruno, A.; Farias, A. Fortaleza: uma breve história. Fortaleza: Edições Demócrito Rocha, 2012.

Câmara Municipal de Fortaleza. 44\% da população de Fortaleza reside em assentamento precários. Canal Oficial da Câmara Municipal de Fortaleza. Fortaleza, 22 ago. 2019. Disponível em: <https://www.cmfor.ce.gov.br/2019/08/22/44-da-populacao-defortaleza-reside-em-assentamentos-precarios-afirma-sargento-reginauro/>. Acesso em: 29 jul. 2020.

Campos, P. H. Os efeitos da crise econômica e da operação Lava-jato sobre a indústria da construção pesada no Brasil: falências, desnacionalização e desestruturação produtiva. Mediações - Revista de Ciências Sociais, v. 24, n. 1, p. 127-153, 2019. https://doi.org/ 10.5433/2176-6665.2019.1v24n1p127

Carneiro, P. R. F.; Miguez, M. G. A flood control approach integrated with a sustainable land use planning in metropolitan regions. Environmental Land Use Planning, v. 1, n. 1, p. 135-158, 2012. https://doi.org/10.5772/2728

Carvalho, E F. Código florestal, relative Verfassungswidrigkeit "and" die Unterschieldlichkeit der Regelung: o tiro pode sair pela culatra. Revista de Direito Ambiental, v. 19, n. 75, p. 261-287, 2014.

Castro, M. N.; Castro, R. M.; de Souza, C. A importância da mata ciliar no contexto da conservação do solo. Revista Eletrônica de Educação da Faculdade Araguaia, v. 4, n. 4, p. 230-241. 2013.

Diaz-Pascacio, E.; Ortega-Argueta, A.; Castilo-Uzcanca, M. M.; Ramirez-Marcial, N. Influence of land use on the riparian zone condition along an urban-rural gradient on the Sabinal River, Mexico. Botanical Sciences, v. 96, n. 2, p. 180-1999, 2018. https://doi.org/ 10.17129/botsci.1858

Fernandes, E.; Cestaro, L. A.; Ataíde, R. M. C. Metodologia para avaliação do zoneamento ambiental urbano: o caso da Zona de Proteção Ambiental do Rio Doce, Natal/RN. Anais do Congresso Ibero-Americano de Estudos Territoriais e Ambientais, p. 1436-1462, 2014.

Fortaleza. Lei Complementar no 62, de 2 de fevereiro de 2009. Institui o Plano Diretor Participativo do Município de Fortaleza. Disponível em: $<$ https://planodiretor.fortaleza.ce.gov.br/wp-content/uploads/simple-file-list/LeiComplementar-no--062-de-02-de-fevereiro-de-2009.pdf> Acesso em: 20 jul. 2020. 
Fortaleza. Lei Complementar no 250, de 03 de julho de 2018. Modifica a Lei Complementar $\mathrm{n}$ - 62, de 02 de fevereiro de 2009, que institui o plano diretor participativo do Município de Fortaleza. Disponível em: <https://leismunicipais.com.br/a1/ce/f/ fortaleza/lei-complementar/2018/25/250/lei-complementar-n-250-2018-modifica-a-leicomplementar-n-62-de-02-de-fevereiro-de-2009-que-institui-o-plano-diretorparticipativo-do-municipio-de-fortaleza>. Acesso em: 19 maio 2021.

Freitas, C. F. S. Regulações territoriais e expansão urbana informal: é possível preservar e incluir? Paranoá: Cadernos de Arquitetura e Urbanismo, n. 19, 2017. https://doi.org/10.18830/issn.1679-0944.n19.2017.02

Freitas, C. Ilegalidade e degradação em Fortaleza: os riscos do conflito entre a agenda urbana e ambiental brasileira. Urbe. Revista Brasileira de Gestão Urbana, v. 6, p. 109125, 2014. https://doi.org/10.7213/urbe.06.001.AC02

Friedmann, J. Planning in the public domain: From knowledge to action. Princeton: Princeton University Press, 1987.

Frota, N. T. S. Planejamento urbano do institucional ao insurgente: uma análise sobre a atuação dos movimentos socioambientais na proteção dos bens comuns urbanos. Fortaleza: Universidade Federal do Ceará, 2018. (Dissertação de mestrado).

Gass, S. L. B.; Verdum, R.; Corbonnois, J.; Laurent, F. Áreas de preservação permanente no Brasil e na França: um comparativo. Revista Franco-Brasileira de Geografia - Confins, v. 27, n. 27. 2016. https://doi.org/10.4000/confins.10829

Huang, C.; Huang, X.; Peng, C.; Zhou, Z.; Teng, M.; Wang, P. Land use/cover change in the Three Gorges Reservoir area, China: Reconciling the land use conflicts between development and protection. Catena, v. 175, p. 388-399, 2019. https://doi.org/10.1016/ j.catena.2019.01.002

IBGE - Instituto Brasileiro de Geografia e Estatística. Indicadores conjunturais. 2019. Disponível em: <https://www.ibge.gov.br/indicadores>. Acesso em: 20 jul. 2020.

IPECE - Instituto de Pesquisa e Estratégia Econômica do Ceará. Perfil municipal de Fortaleza, tema VII: Distribuição espacial da renda individual. Informe n. 2, 2012. Disponível em: <https://www.ipece.ce.gov.br/wpcontent/uploads/sites/45/2018/ 09/Ipece_Informe_42_outubro_2012.pdf>. Acesso em: 15 jul. 2020.

Jalilov, S.; Kefi, M.; Kumar, P.; Masago, Y.; Mishra, B. K. Sustainable urban water management: Application for Integrated assessment in Southeast Asia. Sustainability, v. 10, n. 122, p. 1-22, 2018. https://doi.org/10.3390/su10010122

Kumar, A.; Kumar, S.; Khosla, M. Issues of environmental management of water resource development projects. International Journal of Scientific Engineering and Applied Science, v. 2, n. 3, p. 99-110, 2016.

Leite, L. H.; Barros, V. C. C. D.; Monteiro, M. E. C.; Moras Filho, L. O.; Borges, L. A. C. Permanent preservation areas in Mantiqueira Sierra: Perspectives for regularization along

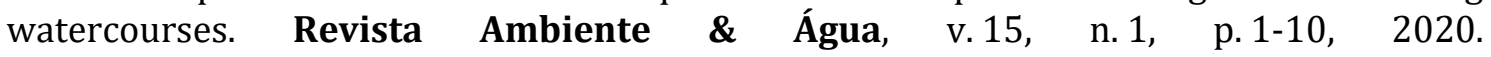
https://doi.org/10.4136/ambi-agua.2422

Lopes, A. M. D.; Alencastro, M. A. C.; Araújo, R. C. P. O licenciamento ambiental em áreas de assentamento de reforma agrária no Estado do Ceará. Revista de Direito Ambiental, v. 13, n. 50, p. $9-27,2008$. 
Lopes, A. M. D’Á.; Tassigny, M. M.; Teixeira, D. M. A redução das áreas de preservação permanente de recursos hídricos pelo novo código florestal e o princípio da proibição proteção deficiente. Revista da Faculdade de Direito da UFG, v. 41, n. 1, p. 46-65, 2017. https://doi.org/10.5216/rfd.v41i1.42049

McGrane, S. J. Impacts of urbanisation on hydrological and water quality dynamics, and urban water management: A review. Hydrological Sciences Journal, v. 61, n. 13, p. 22952311, 2016. https://doi.org/10.1080/02626667.2015.1128084

Milaré, É. Direito do ambiente. São Paulo: Revista dos Tribunais, 2015.

Mota, S. Gestão ambiental de recursos hídricos. 4. ed. Rio de Janeiro: ABES, 2019.

Pan, H.; Deal, B.; Destouni, G.; Zhang, Y.; Kalantari, Z. Sociohydrology modeling for complex urban environments in support of integrated land and water resource management practices. Land Degradation \& Development, v. 29, n. 10, p. 3639-3652, 2018. https://doi.org/10.1002/ldr.3106

Pedroso Júnior, N. N.; Steinmetz, S.; Santos, A. C.; Cruz, J. C. (Orgs.). Estratégia regional para áreas de preservação permanente urbanas. São Paulo: Faculdade Getúlio Vargas, Centro de Pesquisa Jurídica e Aplicada, 2015. (Relatório Final Projeto APPs Urbanas).

Rietveld, L. C.; Siri, J. G.; Chakravarty, I.; Arsenio, A. M.; Biswas, R.; Chatterjee, A. Improving health in cities through systems approaches for urban water management. Environmental Health, v. 15, Suppl. 1, Article number S31, p.151-160, 2016. https://doi.org/10.1186/s12940-016-0107-2

Rocha, T. D. Implicações das mudanças do Código Florestal na delimitação das Áreas de Proteção Permanente da Zona de Proteção Ambiental 9, Natal/RN. Natal: Universidade Federal do Rio Grande do Norte, 2015. (Trabalho de Conclusão de Curso).

Santos, J. O. Vulnerabilidade ambiental e áreas de risco na Bacia Hidrográfica do Rio Cocó: região metropolitana de Fortaleza-CE. Fortaleza: Universidade Estadual do Ceará, 2006. (Dissertação de mestrado).

São Paulo. Lei no 9.866, de 28 de novembro de 1997. Dispõe sobre diretrizes e normas para a proteção e recuperação das bacias hidrográficas dos mananciais de interesse regional do Estado de São Paulo e dá outras providências. Disponível em: <https://www.al.sp.gov.br/norma/5976>. Acesso em: 19 maio 2021.

Sharma, S. Effects of urbanization on water resources: Facts and figures. International Journal of Scientific and Engineering Research, v. 8, n. 4, p. 433-459, 2017.

Silva, L. M. B.; Silva, J. P.; Borges, M. A. L. Do global ao contexto nacional: evolução da política ambiental brasileira. Revista Brasileira de Gestão Ambiental e Sustentabilidade, v. 6, n. 14, p. 593-608, 2019. http://doi.org/10.21438/rbgas.061401

Skrydstrup, J.; Madsen, H. M.; Löwe, R.; Gregersen, I. B.; Pedersen, A. N.; Arnbjerg-Nielsen, $\mathrm{K}$. Incorporating objectives of stakeholders in strategic planning of urban water management. Urban Water Journal, v. 17, n. 2, p. 87-99, 2020. https://doi.org/10.1080/ 1573062X.2020.1748204

Vasconcelos, F. D. M.; Mota, F. S. Gestão ambiental, legislação e os recursos hídricos na Cidade de Fortaleza (CE), Brasil. Revista Brasileira de Ciências Ambientais, v. 55, n. 3, p. 1-18, 2020. https://doi.org/10.5327/Z2176-947820190579

Vasconcelos, F. D. M.; Mota, F. S. B.; Rabelo, N. N.; Dantas, R.; Gama, C.; Silva, L. D. M. M. Gestão e legislação ambiental das unidades de conservação inseridas no Município de Fortaleza/CE. Anais do X Congresso Brasileiro de Gestão Ambiental Fortaleza/CE, 2019.

Rev. Bras. Gest. Amb. Sustent., 2021, vol. 8, n. 19, p. 759-776. 
Vasconcelos, F. P.; Coriolano, L. N. M. T. Impactos sócio-ambientais no litoral: um foco no turismo e na gestão integrada da zona costeira no Estado do Ceará/Brasil. Revista de Gestão Costeira, v. 8, n. 2, p. 259-275, 2008. https://doi.org/10.5894/rgci134

Wang, J.; Lin, Y.; Glendinning, A.; Xu, Y. Land-use changes and land policies evolution in China's urbanization processes. Land Use Policy, v. 75, p. 375-387, 2018. https://doi.org/10.1016/j.landusepol.2018.04.011

Wang, L.; Wang, S.; Zhou, Y.; Zhu, J.; Zhang, J.; Hou, Y.; Liu, W. Landscape pattern variation, protection measures, and land use/land cover changes in drinking water source protection areas: A case study in Danjiangkou Reservoir, China. Global Ecology and Conservation, v. 21, e00827, 2020. https://doi.org/10.1016/j.gecco.2019.e00827

Wang, Y.; Ho, J. K.; Lu, J. Water resources and environmental management. Journal of Water and Climate Change, v. 10, n. 2, p. 3-4, 2019. https://doi.org/10.2166/ wcc.2019.000

Xiang, H.; Zhang, Y.; Richardson, J. S. Importance of riparian zone: Effects of resource availability at land-water interface. Riparian Ecology and Conservation, n. 3, p. 1-17, 2016. https://doi.org/10.1515/remc-2016-0001

Informação da Licença: Este é um artigo Open Access distribuído sob os termos da Licença Creative Commons Attribution, que permite uso irrestrito, distribuição e reprodução em qualquer meio, desde que a obra original seja devidamente citada. 